\title{
Social maturity among obese children in Surakarta, Indonesia
}

\author{
Endang Dewi Lestari, Dwi Hidayah, Suci Murti Karini
}

\begin{abstract}
Background Although it is clear that childhood obesity has association with many aspects included social aspect, the social maturity aspect on childhood obesity is scarcely found.

Objective To examine the prevalence of social maturity and the possible associated factors among obese children.

Methods A cross sectional study was conducted from January to February 2005. Twenty percent of elementary schools in every subdistrict were randomly selected. All obese children from selected schools were recruited to the study after obtaining the informed consent. Criteria of obesity in children was based on BMI e"95 ${ }^{\text {th }}$ percentile according to age and sex. Social maturity was measured using Vineland Social Maturity Scale, which consisted of 8 categories, i.e., self-help general, self-help eating, self-help dressing, selfdirection, occupation, communication, locomotion, and socialization. Social maturity score was determined using age group. The total score was divided into two categories i.e. immature and mature. Possible associated factors with the social maturity such as gender, maternal education less than 9 years, being held back a class, and parental guidance by step mother were analyzed using SPSS 10.0 for Windows.

Results There were 158 obese children recruited in the study. The prevalence of social immaturity was $32.5 \%$. The odds ratio (OR) for parental guidance by single parent or others was $2.32(95 \% \mathrm{Cl}$ $1.01 ; 5.31)$; OR for intelligence was $3.93(95 \% \mathrm{Cl} 1.42 ; 10.89)$; OR for male was $2.41(95 \% \mathrm{Cl} 1.08 ; 5.38)$ and OR for maternal education less than 9 years was $1.22(95 \% \mathrm{Cl} 0.61 ; 2.41)$. Multivariate regression, analysis showed significant association between gender (for male $\mathrm{OR}=2.44 ; 95 \% \mathrm{Cl} 1.06 ; 5.58$ ) and intelligence (OR=3.31; 95\% Cl 1.12;9.84) with social maturity.

Conclusion The prevalence of social maturity in obese children is high. The factors associated with social maturity among obese children are the history of had ever been held back a class and male. Further investigation is needed to find out the understanding of specific influence of social maturity in the prevalence of obesity. [Paediatr Indones 2006;46:174-178].
\end{abstract}

Keywords: social maturity, obese children

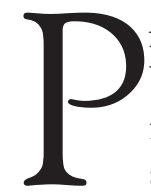
revention to childhood overweight should be begun at early age, since obesity in children is associated with chronic disease in adulthood, such as heart disease, hyper-lipidemia, hyperinsulinemia, hypertension, and atherosclerosis., ${ }^{1,2}$ Obesity involves complex etiological factors including genetic, metabolic and neural frameworks, behavior, food habits, physical activity, and socio-cultural factors. ${ }^{3}$ Behavioral factors can contribute to obesity as they influence food pre-ferences, food intake and food regulation in children. ${ }^{4}$ The risk of obesity among children with both parental obesity is much higher than those who do not have any obese parent. ${ }^{5,6}$ In addition to the genetic factor, family environment may contribute to obesity in children as it influences chronic behavior and has socio-cultural aspects concerning food preferences and food intake among children. The obese children may out of step with their peer group in the daily living. ${ }^{4}$ Obesity brings

Presented at $46^{\text {th }}$ Annual Meeting of the European Society for Paediatric Research, Siena, Italy, August 31-September 3, 2005.

From the Department of Child Health, Medical School, University of Sebelas Maret, Moewardi Hospital, Surakarta, Indonesia.

Reprint requests to: Endang Dewi Lestari, MD, Department of Child Health, Medical School, University of Sebelas Maret, Moewardi Hospital, Surakarta, Indonesia. Tel. 62-271-731227. Fax 62-271-664598. Email: tarndang@yahoo.com. 
not only many physical impacts but also lot of psychosocial impacts in the child development. ${ }^{7}$ Psychosocial problems during childhood period gives important contribution to the future psychological life of a child. ${ }^{8}$ Depressive disorders are found in about $10 \%$ of obese children. ${ }^{9}$ Depression will lead children to increased risk for social difficulties. ${ }^{10}$ Social difficulties and depressive disorders are two different psychological problems that are likely to have association with obese children. ${ }^{9}$ A study in adult showed that there is an association between adolescent depression and deficits in social functioning. ${ }^{11}$

Thus, social problem and obesity is likely to have bidirectional association; social problem may influence the obesity, and vice versa. Social maturity should be measured among children in order to assess the development of social problem. Social maturity is defined as 'performances in respect to which children show a progressive capacity for looking after themselves and for participating in those activities which lead towards ultimate independence as adults'. ${ }^{12}$ Social maturity development plays an important role as a basic for further social functioning. Unfortunately, we could scarcely find the data concerning social maturity development on obese children. The purpose of the study is to investigate the prevalence of social maturity and the possible associated factors among obese children from elementary schools in Surakarta, Indonesia.

\section{Methods}

A cross sectional study on obese children was conducted from January to February 2005 in elementary schools at Surakarta municipal, Central Java, Indonesia. Schools included in the study were randomly selected using estimation of $20 \%$ percent of all elementary schools in every sub-district. Sport instructors from selected school recruited all children without disability who had body mass index (BMI) $\geq 85$ percentile. Body mass index (BMI) is the body weight in kilo-grams divided by the square of height in meters $\left(\mathrm{kg} / \mathrm{m}^{2}\right)$. Afterward they were referred to undergo anthropometric measurement by a team of doctors in a defined day in each subdistrict. All obese children were selected using category of BMI $\geq 95$ percentile and their parents/ caregivers were inter-viewed using questionnaires after obtaining the informed consent. The study protocols were approved by the Research Ethics Committee of Sebelas Maret University, Surakarta, Indonesia.

Age was calculated from the date of birth and rounded to the closest year; that is, $<0.5$ was rounded down to the year below and $\geq 0.5$ was rounded up to the year above. Exact age was used to calculate the body mass index (BMI). Height and weight of each child was measured using the same standard protocol. A sliding weighting scale (International, PT Medifortuna Farm, Bandung, Indonesia) was used to measure the weight of each child. The accuracy of the instrument was re-checked with a calibrated rule both before and after each measuring session. Children were asked to remove shoes, accessories, and heavy clothing items; then children were weighed wearing light cloth in the class room. Height was measured to the nearest $0.1 \mathrm{~cm}$ using a portable microtoise. The feet were placed together with heels, buttocks and shoulder blades against the wall. The head was unstretched and the child was encouraged to relax the shoulders and breaths normally. An average of three readings was taken. Timing of the measurements was in the morning in the class room. The BMI was calculated as weight in kilograms divided by squared height in meters. Obesity rates were determined using age and sex specific BMI cut-off points based on the CDC Chart 2000 BMI reference data. Criteria of obesity in children were based on $\mathrm{BMI} \geq 95^{\text {th }}$ percentile.

Social maturity was measured using Vineland social maturity scale. The Vineland social maturity scale measured social competence, self-help skills, and adaptive behavior from infancy to adulthood by interviewing child and parent or other caregiver. ${ }^{13}$ Personal and social skills were evaluated in the following areas: daily living skills (general self-help, eating, dressing); communication (listening, speaking, writing); motor skills (fine and gross, including locomotion); socialization (interpersonal relationships, play and leisure, and coping skills); occupational skills; and self-direction. The test was untimed and took 20-30 minutes. Raw scores were converted to an age equivalent score. The total score was divided into two categories i.e. immature and mature social in each level of age based on the rule of the Vineland protocol. 
Information about gender, maternal education, intelligence and parental guidance were collected to elaborate possible factors that may contribute to the prevalence of social maturity. Data of these variables were obtained by interviewers using a questionnaire for each respondent. Maternal education was divided into two categories, i.e. less than 9 years and 9 years or more. Intelligence was measured using the history of had ever been held back a class. Parental guidance was divided into two groups i.e. by own mother or step mother. Parental guidance by step mother in this study is defined as the children who live without their own mother.

The prevalence of social immaturity in obese children was calculated using SPSS 10.0 for Windows. Possible associated factors with the social maturity such as gender, maternal education less than 9 years, history of had ever been held back a class; and parental guidance by step mother were analyzed using univariate and multivariate logistic regression from SPSS 10.0 for Windows.

\section{Results}

One-hundred and fifty-eight children met the inclusion criteria. Out of 158, seven children did not attend to the interview for scoring of Vineland social maturity scale, hence 151 children remained as actual study subjects. The subjects characteristics of the sample are presented in Table 1 . The subjects age ranged between 5 to 14 years, with the mean of age were 9 and most subjects were 8 years old. Most subjects were male $(67.5 \%)$ and had maternal education less than 9 years. Eighteen (11.9\%) had ever been held back a class, and 29 (19.2\%) were cared by step mother. The prevalence of social immaturity among obese school children indicated by Vineland score was $32.4 \%$.

Table 1. The subject Characteristics $(\mathrm{N}=151)$

\begin{tabular}{lcc}
\hline \multicolumn{1}{c}{ Characteristics } & $\mathbf{n}$ & $\%$ \\
\hline Gender (male) & 102 & 67.5 \\
Maternal education less than 9 years & 102 & 67.5 \\
Intelligence (history of had ever & & \\
been held back a class) & 18 & 11.9 \\
Parental guidance by step mother & 29 & 19.2 \\
Social immaturity & 49 & 32.4 \\
\hline
\end{tabular}

The possible associated factors with social maturity on obese children were presented in Tables 2 and 3. Univariate logistic regression analysis indicated that gender as male, parental guidance by step mother and intelligence obtained by history of had ever been held back a class had significant result as risk factors associated with the prevalence of social immaturity (Table 2). Multivariate logistic regression analysis showed that male subjects and history of had ever been held back a class (indicated intelligence) were associated with a significantly increased risk of social immaturity among obese children, i.e. 2 times and 4 times respectively (Table 3 ).

TABLE 2. FACTORS INFLUENCING SOCIAL IMMATURITY IN OBESE CHILDREN

\begin{tabular}{|c|c|c|c|}
\hline Factors & Odd Ratio & $\mathbf{P}$ & $95 \% \mathrm{Cl}$ \\
\hline Gender $(\text { male })^{*}$ & 2.41 & 0.03 & $1.08-5.38$ \\
\hline Parental guidance by step mother & 2.23 & 0.05 & $1.01-5.31$ \\
\hline Maternal education $<9$ years & 1.22 & 0.05 & $0.61-2.41$ \\
\hline Held back a class* & 3.93 & 0.01 & $1.42-10.89$ \\
\hline
\end{tabular}

* significant result

Table 3. Multivariate odds ratio and $95 \%$ confidence INTERVAL OF POSSIBLE ASSOCIATED FACTORS WITH SOCIAL IMMATURITY IN OBESE CHILDREN

\begin{tabular}{lccc}
\hline \multicolumn{1}{c}{ Factors } & Odd Ratio & $\mathbf{P}$ & $\mathbf{9 5 \%} \mathbf{~ C l}$ \\
\hline Gender (male) $^{*}$ & 2.44 & 0.04 & $1.06-5.58$ \\
Parental guidance by step mother $^{*}$ & 1.70 & 0.24 & $0.69-4.197$ \\
Maternal education $<9$ years & 1.24 & 0.56 & $0.60-2.55$ \\
Held back a class* $^{*}$ & 3.31 & 0.03 & $1.12-9.84$ \\
\hline
\end{tabular}

\section{Discussion}

The study demonstrated high prevalence (32.4\%) of social immaturity among obese children. This result is bigger than the prevalence of depressive disorders in obese children. ${ }^{9}$ Previous prevalence study of social immaturity data in obese children are scarcely found. Social maturity is measured by how well a person fits into the actions of expectations of their peer group. Physical condition has association with the prevalence of social maturity. ${ }^{14}$ Obesity is a chronic physical condition which may cause one to suffer from social stigmatization and discrimination. It may contribute in increasing the risk of social immaturity and in the contrary, social immaturity may lead to the oc- 
currence of obese children by practicing bad eating habit and indiscipline activities. Obese children usually used to be out of control when eating. ${ }^{15}$ It is also believed that obesity in children is resulted from lack of willpower or laziness. ${ }^{15}$

Parental guidance by step mother in this study is defined as the children who live without their own mother. Children coming from family with problematic parents may be unsupervised for long periods as parents are busy with their own works or their own problem. ${ }^{16}$ Household problem can lead to disruptions in affection, discipline, and even the daily household routines, such as meals and bedtimes. ${ }^{16,17}$ Most children of parents with a problem go below the normal range of adjustment on standardized measures; therefore they are at a higher risk for adjustment problems than children from intact families. ${ }^{18}$ Univariate analysis indicated that guidance by step mother was associated with social immaturity among obese children. The result is reasonable, since social maturity is widely influenced by parental guidance. ${ }^{14}$ Step mother is probably very busy with her works, which eventually make her ignore the child social development. However, after doing adjustment using multivariate analysis, the association of parental guidance by step mother with the prevalence of social maturity became not significant. This result is also supported by another evidence revealed that children from divorce families exhibited greater maturity. ${ }^{16}$ The Vineland adaptive behavior scales sets the standard for measuring personal and social skills used for everyday living. This assessment provides critical data for the diagnosis or evaluation of a wide range of disabilities including functional skills impairment. ${ }^{13}$

Social maturity is also influenced by intelligence, teacher guidance, and environment. ${ }^{14}$ The study showed that the grade of intelligence reflected by the history of had been held back a class had significant association with social immaturity. It is assumed that all subjects came from the same environment and were educated by the same teacher guidance by using random sampling in selecting participated schools.

Other factor found to be significant is gender (male) which is still unclear. ${ }^{14}$ However, the current study reveals that gender as male is more likely to have consequence of social immaturity development than female. It probably means that during childhood pe- riod, the achievement of social maturity development in females is more rapid than in male.

The limitation of this study is that we could not conclude that the association between significant factors and social maturity is a causative association, since the study design was a population based cross sectional study. However, the present finding is of interest considered the paucity of data concerning the prevalence of social maturity in obese children. These findings, particularly the prevalence of social immaturity among obese children has important public health and clinical implication. Obesity is a chronic disease; overnutrition will increase the incidence of obesity. Furthermore, nutrients play a role in modulating the expression of genes that influence the energy metabolism, cell differentiation and cell growth for further impact in being obese. ${ }^{19}$ Awareness for being obese is important way to prevent children becoming obese. The clinician should approach the family to prevent children having over-nutrition's life style by promoting active and healthy life style. When clinicians face obese patients, they are supposed to provide enough time to counsel parents to encourage healthy daily living habits by scheduling the activities, bed time and eating time. Encouraging to change the bad eating habit and to have activities in a discipline way are the important points that must be advised to the obese children and their family during clinical session.

In conclusion, the prevalence of social immaturity among obese children in Surakarta was 32.5\%. Factors influencing social immaturity are gender and intelligence. Despite the potential limitations, this findings is of interest and further investigations is needed to understand the specific influence of social maturity to the prevalence of obesity. In addition, the intervention to decrease the prevalence of obesity should be emphasized to changing behavior and keeping activities in a discipline way and a healthy life style.

\section{Acknowledgments}

We would like to thank to Damayanti R. Syarief, MD, PhD for contributing to the study as the chief of a multicenter study on obese children, and for giving the consultation in conducting the research. Many thanks also go to Reza, MD and Martuti, MD for their assistance in the data collection. 


\section{References}

1. Nelson JA, Chiasson MA, Ford VF. Childhood overweight in a New York City WIC population. Am J Public Health 2004;94:458-62.

2. Reilly JJ, Wilson ML, Summerbell CD, Wilson DC. Obesity: Diagnosis, prevention, and treatment; evidence based answers to common questions. Arch Dis Child 2002;86:392-5.

3. Nammi S, Koka S, Chinnala KM, Boini KM. Obesity: An overview on its current perspectives and treatment options. Nutrition Journal 2004;3:3.

4. Birch LL, Fisher JO. Development of eating behaviors among children and adolescents. Pediatrics 1998;101: 539-49.

5. Garn SM, Clark DC. Trends in fatness and origins of obesity. Pediatrics 1976;57:443-56.

6. Whitaker RC, Wright JA, Pepe MS, Seidel RD, Dietz WH. Predicting obesity in young adulthood from childhood and parental obesity. N Engl J Med 1997;337:869-73.

7. Dietz WH. Health consequences of obesity in youth: Childhood predictors of adult disease. Pediatrics 1998;101:518-25.

8. In: Vostanis P, Grattan E, Cumella S. Mental health problems of homeless children and families: Longitudinal study. Br Med J 1998;316:899-902.

9. Tansey M. Childhood obesity. Available from: URL: http://www.vh.org/pediatric/providers/obesity/index.html
10. Boykin CL, Harper DC. Depression in children and adolescents. Available from:URL:http://www.vh.org/ pediatric/provider/pediatrics/depression/index.html

11. Lewinsohn PM, Rohde P, Seeley JR, Klein DN, Gotlib $\mathrm{IH}$. Psychosocial functioning of young adults who have experienced and recovered from major depressive disorder during adolescence. J Abnorm Psychol 2003;112(3):353-63.

12. Doll EA. Vineland Social Maturity Scales. Washington: American guidance services inc.; 1966.

13. Gale encyclopedia of childhood and adolescence. The Vineland social maturity scale. Available from: URL: http://www.findarticles.com/p/articles/mi_g2602/is_0005/ ai 2602000531

14. Hurlock EB. Child development for the pediatrician. Pediatr Clin North Amer 1982;29:359-75.

15. Barlow SE, Dietz WH. Obesity evaluation and treatment: Expert committee recommendations. Pediatrics 1998;102:E29.

16. Emery RE, Coiro MJ. Divorce: Consequences for children. Pediatr Rev 1995;16:306-10.

17. Conway J. Prescription for poor health: The crisis for homeless families. London: LFC, Maternity Alliance, SHAC, Shelter; 1988.

18. Amato PR. Life-span adjustment of children to their parents' divorce. Future Child 2004;4:143-64.

19. Harland JI. Nutrition and genetics: Mapping individual health. ILSI Europe Concise Monographs Series 2005:1-31. 